\title{
Undertaking and building a culture of child/youth involvement in a context of Children's Trust Partnerships
}

Martin Bailey, Participation Manager, Children Schools and Families, Hertfordshire County Council, UK. (martin.bailey@hertscc.gov.uk )

Wendy Wills, Centre for Research in Primary and Community Care (CRIPACC), University of Hertfordshire, UK

\section{Context}

This viewpoint discusses some theoretical and practical issues which deserve consideration in the drive to build a culture of children and young people's involvement in decision-making, when staff work in partnership with others across traditional professional and organisational boundaries. Some of these issues have arisen through the first author's practice as a participation manager in Hertfordshire (UK) and some from his research evaluating best practice guidance for child/youth involvement when working within partnership arrangements. The second author has experienced these partnership arrangements as a researcher commissioned by the participation team; her primary concern is assuring that the views of children and young people are heard. Whilst children's services in England and Wales are arranged through Children's Trust Partnerships, the issues discussed are intended to be applicable in any setting where organisations work together to improve the lives of children and young people. This paper explores some of the difficulties in developing child/youth involvement and offers some ideas on ways forward. First, some of the challenges are explored.

\section{A clash of cultures}

In England and Wales, children's services arrangements have changed significantly in recent years. Local authorities and their partner agencies, such as social services, education, health and the police are collectively responsible for the wellbeing of children and young people aged up to 18 years (or 25 years for young people with a disability). These organisations are required to work together as a Children's Trust Partnership. This requirement has arisen from two distinct failings. Poor co-ordination of services meant that many families had to tell their story a number of times when they received services and assessments from different agencies. This often led to fragmented provision (Audit Commission, 2003). Secondly, the inquiry into the death of Victoria Climbie at the hands of members of her extended family with whom she lived, found a lack of joint working across children's services (Laming, 2003). As a result, the Children Act 2004 places a duty on local authorities to promote co-operation between agencies through Children's Trust Partnerships to improve children's well-being. The Children Act 2004 creates an integrated framework of inspection to measure progress in improving outcomes for children. Children's Trust Partnerships and their constituent agencies are legally required to consult and involve children and young people in a number of different decisions. They must also ensure that the workforce has the necessary 
skills and knowledge to involve children and young people in decision-making. Whilst this may be seen to bring benefits, there may also be a clash of cultures.

Children's Trust Partnerships are a multi-dimensional concept which requires a 'change management' approach, focussing on how managers oversee and support staff to adopt new ways of working and dealing with their hopes, fears and ambitions (IdEA, 2007). Children and young people's involvement in decisionmaking is also a multi-dimensional concept which requires organisational change (Willow, 2005). Tensions between these two multi-dimensional concepts may exist. The challenge for Children's Trust Partnerships therefore is to develop a change management programme which can both build a culture that embeds child/youth involvement and engenders a partnership approach to improve the well-being of all children and young people. This in itself brings many challenges.

\section{A partnership view of children and childhood}

Traditionally, many adults and organisations have viewed children and young people as passive actors and biologically determined (Moss and Petrie, 2004). They are often viewed as needy, vulnerable or bad, as having few opinions or feelings and as having fewer rights than adults (Williamson, 2003). Children and young people are often viewed as those in need of protection and those who others need protection from (Prout, 2005).

A challenge for children's services is that different organisations or professions, some specific to the local context, may have differing perspectives on what childhood is and what children are. Do social workers have a protectionist view of children? Do the police view young people as people others need protection from? Do schools view children and young people as having fewer rights than adults? These differences will have an impact on the values and principles of a partnership, the priorities it focuses on and the way in which these are implemented.

However, the concept of children's involvement in decision-making is embodied within the United Nations Convention on the Rights of the Child (UNICEF 1989). The UNCRC regards children and young people as citizens in their own right, deserving some level of autonomy over their own lives. It regards children and young people as living in the present and not merely adults of the future (Skelton, 2007). This concept of childhood is at odds with the traditional views mentioned earlier. A critical issue is that the UNCRC is an international treaty but it is not legally enforceable in the UK, although some articles within it are built into legislation and policy and it can be cited in court cases. Children's Trust Partnerships are not required by law to adopt or implement the convention.

The development of a culture of child/youth involvement within the Children's Trust Partnership needs to be based on a concept of the competent child who has the right, the need and the ability to participate in decision-making. To do this, children's services need to have a dialogue with themselves and with the children and young people they serve to understand their current concept/s and agree a common perspective of childhood. Basing these discussions on principles and values embodied within the UNCRC would help to overcome some of these cultural tensions and provide agreed ways forward for all. 


\section{Using a common language and understanding of power}

Participation is a complex term with no universal definition. It can be used to describe the extent to which children and young people are involved in a decisionmaking process. It can describe the role that children and young people play and which part of the decision-making processes they are involved in. Participation can also refer to the breadth of activity which the Children's Trust Partnership encompasses or it is used to describe the 'organisational culture'.

There are a number of models to describe power sharing between adults and children and young people and these can be grouped under three types: a hierarchical model, a non-hierarchical model and an organisational culture model. The hierarchy of participation model was originally developed by Arnstein (1969) and has since been adapted by Hart (1992). This model emphasises the need to give more power to children and young people to enable them to take part in decision-making. It comes under criticism from some as it suggests that anything short of the 'top rungs' is a failure. The non-hierarchical model (Tresseder, 1997) suggests that levels of power differ and that these different levels are legitimate at different times and in varying contexts. This comes under criticism as it can support the status-quo of adult led decision-making too easily. The organisational culture model (Kirby et al, 2003; Shier, 2001) introduces the concept of organisational change needed to enable children and young people to take part in decisionmaking and is given support by many authors and organisations.

The problem arises when different organisations, professions or individuals have a different meaning of participation and use different models of power-sharing. Time and energy can be wasted arguing over whether or not a piece of work is participation or consultation. This is mostly likely due to staff not having received sufficient training and therefore not acknowledging that they are practicing from a mixed theoretical perspective.

Two things can help. The terms involvement or engagement are increasingly regarded as overarching terms which describe the inclusion of children and young people in any form of decision-making (Burke, 2008). Children and young people should have different amounts of power dependent on the child's capacity and the perceived risk (Lansdown, 1995). One of the key challenges for organisations working in partnership with each other is to be clear on the language and model it adopts and uses and to be clear as to why these choices have been made.

\section{Insider Researcher}

On many occasions, projects to consult or involve children and young people are commissioned via a consultation or research organisation. Alternatively, the work is often undertaken by a dedicated worker, a participation team or a member of staff from within the constituent organisation. The decision to undertake research internally or commission an external contractor may be based on resources and capacity rather than theoretical consideration and this therefore may have significant implications for practice, data quality and the validity of findings. 
Work is often commissioned externally because there is a belief that children and young people will only be truly 'honest' with an external contractor. At other times the organisation may not have the skills or capacity to undertake the work. Commissioning work externally may be in contradiction to the concept of building a culture of child/youth involvement as it is the staff and the organisation that needs to develop relationships with children and young people so that they become a 'listening organisation'. Staff employed within the organisation may be subject to pressure to meet organisation requirements and are not able to champion children and young people's voices.

Whilst there is clearly a role for external experts to undertake some aspects of child/youth involvement work, children's services must also learn to undertake work themselves. This issue becomes more significant during the current global financial difficulties as budgets are under pressure and resources are scarce. Despite these challenges, it is important that Partnerships identify ways to undertake robust research themselves and seek the necessary training to ensure this happens consistently.

The concept of insider research can help children's services to make these choices. According to Brannick and Coghlan (2007), an insider researcher is when the full research project is undertaken by someone who is part of the organisational system within which the research is taking place. It can be undertaken within all of the major research paradigms (e.g. positivism, hermeneutics, and action research). The challenge is that bias may increase because the 'researcher' is not independent. However, insider research should be valued because it is the very experience of the practitioner who is best able to make such a distinctive contribution to the development of knowledge about the organisation they are inside (Coghlan, 2003). Focus should be on using an appropriate methodology, the quality of the data collected and the national and local political and ethical challenges (Anderson and Jones, 2000). A process of reflexivity is essential to reduce power imbalances between the researcher and the subjects (Arber, 2006). Taking such steps should increase the validity of the research.

The challenge for children's services is to know when to undertake the work through dedicated participation workers, when to support an individual practitioner and when to commission the work externally. Building partnerships to include or draw on the knowledge of external research experts (academic researchers or commissioned research companies, for example) would be a step forward.

\section{Using the concept of spatiality to help understand the different decisions which children and young people must be involved in}

Children and young people have the right to be involved in an increasing number of decisions. These include decisions about education, the development of local community leisure time activities and being involved in strategic decision-making for children's services. Children and young people must be involved in individual assessments or care plans and children in need are entitled to independent advocacy to help them do this. A challenge for children's services, particularly when working in partnership with each other is to make sense of these different decisions 
and to develop effective strategies, policies and mechanisms for staff to have the necessary skills to enable this to happen. These decision types are often categorised in different ways, for example public and personal (Kirby et al, 2003) and, often, according to the service which is being provided. However, children's services are also arranged geographically, across local communities, towns, cities, regions and countries. Children's services also work with families in their homes. The concept of spatiality (Horton et al, 2008) is important here. This could provide an alternative way to examine and understand the different decisions which children and young people should be involved in. By doing so, it could help to understand and challenge the different barriers to child/youth involvement, help develop more effective methods for participation and ensure feedback mechanisms are implemented to enable children's participation rights to be upheld. The table below gives some examples. These headings to describe three possible different spaces should not be regarded as anything more than a starting point for discussion with children and young people themselves to explore the spaces which make sense to them in relation to the different decisions they should be involved in.

Table 1. Spatiality and examples of child/youth involvement in decision making

\begin{tabular}{|l|l|}
\hline \multicolumn{1}{|c|}{ Types of space } & \multicolumn{1}{c|}{ Examples of child/youth involvement } \\
\hline $\begin{array}{l}\text { The home (domestic and } \\
\text { corporate) }\end{array}$ & $\begin{array}{l}\text { Child protection conferences } \\
\text { Assessments of need } \\
\text { Access to independent advocacy }\end{array}$ \\
\hline $\begin{array}{l}\text { The local community } \\
\text { (village, town, city etc) }\end{array}$ & $\begin{array}{l}\text { Teaching and learning decisions at school } \\
\text { Development of local crime strategies } \\
\text { Development of local positive leisure activities } \\
\text { Decision-making about health provision } \\
\text { Consultation by local government }\end{array}$ \\
\hline $\begin{array}{l}\text { The wider community } \\
\text { (county, region, national } \\
\text { etc.) }\end{array}$ & $\begin{array}{l}\text { Direct dialogue with children's services director as part } \\
\text { of governance arrangements for 'looked after' children } \\
\text { Involvement with large voluntary sector organisations } \\
\text { Consultation by regional or national government }\end{array}$ \\
\hline
\end{tabular}

\section{Conclusions}

Services to promote the well being of children and young people are often required to work in partnership with each other and must also involve children and young people in many different forms of decision-making. This may bring benefits, but also a number of theoretical and practical tensions.

On one hand, undertaking child/youth involvement can be relatively easy. If one believes that children and young people have the right, the need and the ability to participate, then staff and organisations will find ways to do this. If this value base is not held, however, many barriers will surface to prevent it from happening. When 
the practice and the development of child/youth involvement are within children's services, specific challenges are found. To overcome these, the following may help:

- Integrate child/youth involvement into a programme of change management in order to reduce tensions and to build partnerships which involve children and young people in all forms of decision-making.

- Undertake dialogue about perceptions of childhood, how different professions and organisations understand, promote and uphold children's rights and what this might mean in relation to organisational priorities.

- Explore the different professional standards and codes of practice which may result in different approaches to undertaking and embedding child/youth involvement and develop shared standards which relate to all forms of decision-making.

- Adopt a common language about child/youth involvement and a common model for power-sharing, so that constituent organisations and professions are able to communicate effectively with each other.

- Consider the theoretical and practical issues of commissioning work to external specialists, supporting practitioner research and undertaking insider research.

- Consider how the concept of spatiality can help understandings about the different structures and practices which children and young people must be involved in.

\section{References}

Anderson, G.L. and Jones, F. (2000) Knowledge Generation in Educational Administration from the Inside Out: The Promise and Perils of Site-Based, Administrator Research. Educational Administration Quarterly; 36; 428.

Arber, A. (2006) Reflexivity: A Challenge for the Researcher as Practitioner? Journal of Research in Nursing. 11; 147.

Arnstein, S. R. (1969) A Ladder of Citizen Participation. Journal of the American Institute of Planning. 35(4):216-224.

Audit Commission (2003) Services for Disabled Children: A Review of Services for Disabled Children and their Families. London, Audit Commission.

Brannick, T. and Coghlan, D. (2007) In Defense of Being "Native": The Case for Insider Academic Research 2007. Organizational Research Methods 10; 59 
Burke, T. (2008) Listen and Change: A guide to Children and Young Peoples Participation Rights. Children's Rights Alliance for England (CRAE). London. Children's Rights Alliance England.

Coghlan, D. (2003) `Practitioner Research for Organisational Knowledge. Mechanistic and Organistic-Oriented Approaches to Insider Action Research', Management Learning 34 (4): 341-463.

Hart, R. (1992) Children's Participation: From Tokenism to Citizenship. United Kingdom. UNCEF/Save the Children.

Horton, J., Kraftl, P. and Tucker, F. (2008) 'The challenges of 'Children's Geographies': a reaffirmation', Children's Geographies, 6(4):335 -348.

IDeA (2007) Managing Significant Change: Version: 4 An Introduction to Programme, Project and Change Management for Members and the Corporate Management Team. England. http://www.idea.gov.uk/idk/aio/6056926

Laming, Lord. (2003) The Victoria Climbie Inquiry. Presented to Parliament by the Secretary of State for Health and the Secretary of State for the Home Department,

Lansdown, G. (1995) The Evolving Capacities of the Child - Italy. UNICEF Save the Children - Innocenti Insight.

Moss, P. and Petrie, P. (2002) From Children's Services to Children's Spaces: Public Policy, Children and Childhood. London, Routledge,

Prout, A. (2005) The Future of Childhood: Towards the Interdisciplinary Study of Children, London.Routledge Falmer,

Shier, H. (2001) Pathways to Participation: Openings, Opportunities and Obligations. Children and Society, 15: 107-111.

Skelton, T. (2007) Children, Young People, UNICEF and Participation. Children's Geographies, 5 (1): 165-181

Tresseder, P. (1997) Empowering Children and Young People. London, Children's Rights Office and Save the Children.

UNICEF (1989) The United Nations Convention on the Right of the Child. Geneva, Office of the United Nations High Commissioner for Human Rights

Williamson, B. (2003) The Grit in the Oyster: Final Report of the Evaluation of Investing in Children. Durham, Durham County Council.

Willow, C. (2005) Ready, Steady, Change. England. Children's Rights Alliance England/DfES. 